\title{
Renal kallikrein in diabetic patients with hypertension accompanied by nephropathy
}

\author{
T. Baba ${ }^{1}$, S. Murabayashi ${ }^{1}$, T. Ishizaki ${ }^{2}$, Y. Ido ${ }^{1}$, K. Aoyagi ${ }^{1}$ and K. Takebe ${ }^{1}$ \\ 'Third Department of Internal Medicine, Hirosaki University School of Medicine, Hirosaki, and \\ ${ }^{2}$ Division of Clinical Pharmacology, Clinical Research Institute, National Medical Center, Tokyo, Japan
}

\begin{abstract}
Summary. We measured the 24-h excretion of urinary kallikrein in 27 patients with Type 2 (non-insulin-dependent) diabetes and in 10 normal control subjects. Mean $( \pm S D)$ kallikrein excretion in diabetic patients with nephropathy $(6.2 \pm$ 2.4 naphthyl units (NU)/day, $n=13$ ) was significantly lower than in control subjects $(12.8 \pm 3.4 \mathrm{NU} /$ day, $p<0.01)$ and in diabetic patients without nephropathy $(9.4 \pm 3.4 \mathrm{NU} /$ day, $n=14, p<0.05)$. Kallikrein excretion in hypertensive diabetic patients with nephropathy $(5.1 \pm 1.6 \mathrm{NU} /$ day, $n=8)$ was significantly lower $(p<0.05)$ than in normotensive patients with nephropathy $(8.3 \pm 2.1 \mathrm{NU} /$ day, $n=5)$. There were no significant differences in kallikrein excretion rate (24-h excretion of urinary kallikrein/24-h creatinine clearance) among control subjects $(9.9 \pm 4.3 \mathrm{NU} / \mathrm{ml})$, diabetic patients with $(9.0 \pm$ $3.2 \mathrm{NU} / \mathrm{ml})$ and without $(9.3 \pm 3.5 \mathrm{NU} / \mathrm{ml})$ nephropathy. However, kallikrein excretion rate in hypertensive diabetic patients with nephropathy $(7.7 \pm 3.3 \mathrm{NU} / \mathrm{ml})$ was significantly lower $(p<0.05)$ than in normotensive diabetic patients with
\end{abstract}

nephropathy $(11.8 \pm 2.0 \mathrm{NU} / \mathrm{ml}, n=10)$. Respective basal and post-stimulated (with intravenous furosemide $40 \mathrm{mg}$ plus 60 min ambulation) plasma aldosterone concentrations measured in control subjects and in hypertensive diabetic patients with nephropathy were similar and increased to the same extent in the 2 groups $(5.5 \pm 3.2$ versus $5.3 \pm 3.2$ and $9.3 \pm 2.6$ versus $10.5 \pm 3.4 \mathrm{ng} / \mathrm{ml}$ ), although the respective plasma renin activity tended to be lower in diabetic patients than in control subjects $(0.7 \pm 0.6$ versus $1.3 \pm 0.9$ and $1.8 \pm 1.8$ versus $3.0 \pm$ $\left.2.6 \mathrm{ng}^{-1} \cdot \mathrm{ml}^{-1} \cdot \mathrm{h}^{-1}\right)$. The results indicate that urinary kallikrein excretion is decreased in hypertensive diabetic patients with nephropathy, and that the decrease might not be attributable to an altered renin-aldosterone system.

Key words: Renal kallikrein, urinary kallikrein excretion, diabetes mellitus, hypertension, nephropathy, plasma aldosterone concentration, plasma renin activity.
It has been reported that the prevalence of hypertension in diabetic patients is greater than in non-diabetic subjects [1-3]. The development of hypertension appears to be associated with diabetic nephropathy in patients with Type 1 (insulin-dependent) diabetes [4] and in those with Type 2 (non-insulin-dependent) diabetes [5]. However, the precise mechanism(s) for developing hypertension in diabetes mellitus has not yet clearly been elucidated. The kidney is known to produce and secrete vasodilator-system substances such as prostaglandins and kallikrein, as well as the vasoconstrictor-system substance, renin. Although much emphasis has been placed on the activity of the renin-angiotensin system [6-9], the vasodilator system has been relatively ignored [10]. The renal kallikrein-kinin system has been proposed to be involved in regulating water and electrolyte transport at the site of the distal nephrons [11]. However, there are almost no reports which discuss the renal kallikrein-kinin system in diabetes mellitus in relation to diabetic nephropathy and/or hypertension. This study was designed to examine the urinary kallikrein excretion profiles in patients with Type 2 diabetes who did and did not have high blood pressure with and without nephropathy.

\section{Subjects and methods}

\section{Subjects}

Twenty-seven Type 2 diabetic patients $(11$ males and 16 females aged $52.5 \pm 8.0$ years, mean $\pm \mathrm{SD}$ ), whose plasma glucose levels were relatively well controlled, and 10 normal control subjects without a family history of hypertension and without taking any medication (6 males and 4 females aged $48.3 \pm 7.9$ years), were studied. Informed consent had been obtained from each of the subjects.

Patients were selected prospectively for the study on the basis of age (30-65 years), duration of diabetes (3-15 years) and 24-h urinary albumin excretion data. The patients associated with urinary tract infection were excluded from the study. None of them had received any 
antihypertensive agents (i.e. diuretic, beta-blocker, calcium antagonist), fibrinolytic (i. e. urokinase) or ascorbic acid during at least 2 weeks preceding the study. These patients selected prospectively were divided into 2 groups according to the absence (Group A, $n=14$ ) or presence (Group B, $n=13$ ) of nephropathy. Those patients in the 2 groups were further subdivided retrospectively according to the absence or presence of hypertension: normotensive and hypertensive patients in Group A are, henceforth, designated as A-N and A-Hy respectively, and those in Group B as B-N and B-Hy in the same manner. The clinical characteristics of each group pertinent to the present study are summarized in Table 1 , which gives the data for blood pressure, serum creatinine, creatinine clearance (CCr or GFR), plasma renin activity (PRA) and urinary albumin excretion obtained before each of the subjects was enrolled in the study. In addition, the respective mean $( \pm \mathrm{SD})$ values for haemoglobin $\mathrm{A}_{1 \mathrm{c}}$ were $6.4 \pm 0.9,6.7 \pm 1.1$, $6.9 \pm 0.8$ and $6.2 \pm 0.7 \%$ of total in Groups A-N, A-Hy, B-N and B-Hy. The individual value for haemoglobin $\mathrm{A}_{1 \mathrm{c}}$ in normal control subjects was within the normal limit (ranging from 3.8 to $5.8 \%$ of total, with a mean of $4.8 \pm 0.5 \%$ ). The respective mean durations of diabetes were $6.1 \pm 3.8,4.8 \pm 1.1,11.6 \pm 1.4$ and $12.8 \pm 3.5$ years in Groups A-N, A$\mathrm{Hy}, \mathrm{B}-\mathrm{N}$ and B-Hy. The mean durations of diabetes in patient groups with nephropathy (B-N and B-Hy) were significantly $(p<0.01)$ longer than those in the groups without nephropathy ( $\mathrm{A}-\mathrm{N}$ and $\mathrm{A}-\mathrm{Hy}$ ).

\section{Diagnostic criteria}

The diagnosis of diabetes was made by the results of the 75-g oral glucose tolerance test. A subject was classified as having diabetes according to the criteria of the National Diabetes Data Group [12]. The diagnosis of hypertension was confirmed when the mean systolic blood pressure of three successive measurements on different occasions was $160 \mathrm{mmHg}$ or greater, and/or the mean diastolic blood pressure was $90 \mathrm{mmHg}$ or greater. Blood pressure was measured by mercury sphygmomanometry in the right arm with the subject seated, his or her arm resting on a desk and with the same observer performing all the measurements. The diastolic reading was taken as the level at which the sound disappeared (phase V). The diagnosis of nephropathy was made when 24-h urinary excretion of albumin, which was determined by radioimmunoassay (intraassay coefficient of variation, $\mathrm{CV}, 5.4 \%$ ) [13], exceeded $200 \mathrm{mg}[14,15]$.

\section{Study design and measurements}

All subjects were advised to consume a diet containing approximately $8-10 \mathrm{~g} /$ day of $\mathrm{NaCl}$ for 2 weeks before and during the study. A 24-h urine sample was collected for 2 days from each of the subjects for measuring kallikrein, sodium and creatinine excretions. The average of these 2 values obtained from the 24-h samples collected for 2 days was calculated. On a separate day (within a week before urine samplings as described above), venous blood samples were obtained from all the subjects at 09.00 hours for measuring PRA after each subject had been kept in the supine position for at least $30 \mathrm{~min}$. In addition, blood samples were taken from the control subjects and from the Group B-Hy patients for measuring plasma aldosterone concentrations (PAC) and PRA before and after each subject had been kept in the upright position for $60 \mathrm{~min}$ following an intravenous administration of furosemide ( $40 \mathrm{mg}$ bolus). The data were compared between these 2 groups. This part of the study was, however, not performed in the other groups of diabetic patients.

Urinary kallikrein was determined by measuring its esterolytic activity using L-prolyl-L-phenylalanyl-L-arginine- $\alpha$-naphthylester (ProPhe-Arg-NE) as the substrate [16]. Briefly, to $0.1 \mathrm{ml}$ of each urine sample were added $0.1 \mathrm{ml}$ of substrate solution containing $3 \mathrm{mmol}$ Pro-Phe-Arg-NE (Sanwa Kagaku Kenkyusho, Nagoya, Japan) and $1.0 \mathrm{ml}$ of $100 \mathrm{mmol}$ sodium phosphate buffer ( $\mathrm{pH} 7.0$ ) containing $0.03 \%$ sodium dodecyl sulfate. Incubations were carried out at $37{ }^{\circ} \mathrm{C}$ for $30 \mathrm{~min}$ to hydrolyze the substrate (A1). A blank test was done by incubating the mixture without the substrate (A2) or the mixture without the sample urine (A3). After the incubation, $0.1 \mathrm{ml}$ of $1 \%$ solution 


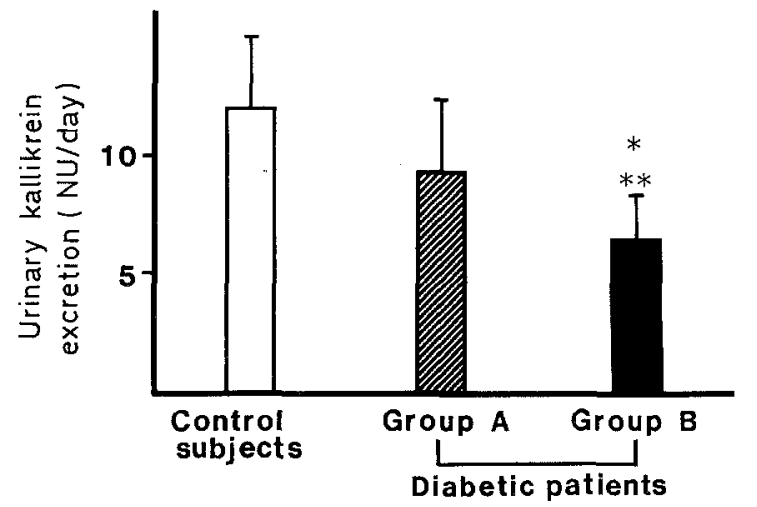

Fig. 1. Urinary kallikrein excretion expressed in naphthyl units (NU) per day in the three study groups. Type 2 diabetic patients with nephropathy (Group B, $n=13$ ) excreted the least amount and differed significantly $(p<0.05)$ from those without nephropathy (Group A, $n=14)$ and $(p<0.01)$ from the normal control subjects $(n=10)$. Data are presented as mean \pm SD. ${ }^{*} p<0.05$ from Group A Type 2 diabetic patients; $* *<0.01$ from control subjects

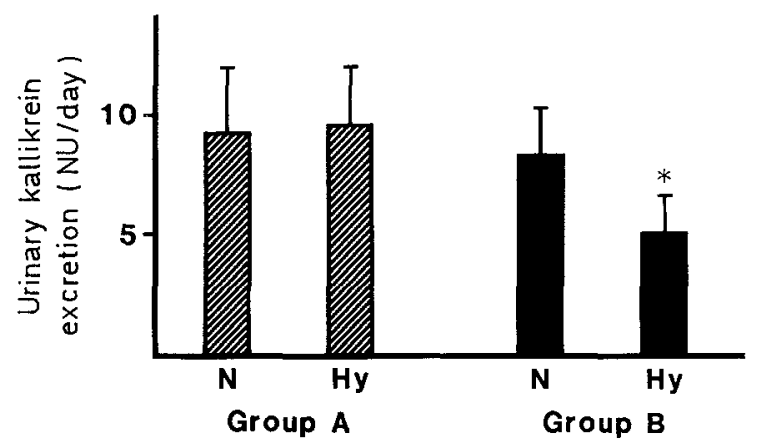

Fig. 2. Urinary kallikrein excretion in the 4 subdivided groups of Type 2 diabetic patients. Hypertensive patients with nephropathy (Group B-Hy, $n=8$ ) excreted the least amount and differed significantly $(p<0.05)$ both from normotensive patients with nephropathy (Group B-N, $n=5$ ) and from normotensive patients without nephropathy (Group A-N, $n=10$ ). The difference between Group B-Hy patients and hypertensive patients without nephropathy (Group A-Hy, $n=4)$ did not reach significance $(p<0.1)$. The data are presented as mean \pm SD. ${ }^{*} p<0.05$ from Group A-N and from Group B-N Type 2 diabetic patients. $\mathrm{NU}=$ naphthyl units

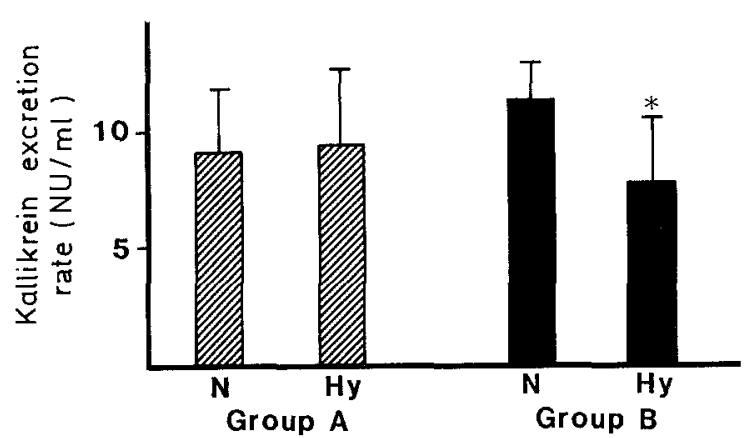

Fig. 3. Kallikrein excretion rate in the 4 subdivided groups of Type 2 diabetic patients. Kallikrein excretion rate is calculated from a $24-\mathrm{h}$ urinary excretion of kallikrein divided by a $24-\mathrm{h} \mathrm{CCr}$ (GFR) using the same urine sample collected on the same day and expressed as NU/ $\mathrm{ml}$. Kallikrein excretion rate in hypertensive diabetic patients with nephropathy (Group B-Hy) was significantly lower $(p<0.05)$ than in normotensive diabetic patients with nephropathy (Group B-N). Otherwise, there were no significant differences among the mean values for kallikrein excretion rate. The data are presented as mean \pm SD. ${ }^{*} p<0.05$ from Group B-N Type 2 diabetic patients. NU $=$ naphthyl units of Fast Red ITR salt was added, and the mixture was allowed to stand at $37{ }^{\circ} \mathrm{C}$ for $5 \mathrm{~min}$ until $1.0 \mathrm{ml}$ of acetic acid was added. Absorbance of the color developed by the diazo-coupling reaction was measured at $475 \mathrm{~nm}$ by a spectrophotometer (Hitachi 228-A, Tokyo, Japan). The absorbance due to the kallikrein activity was calculated as [A1-(A2 + A3)]. Enzyme activity was estimated from the standard curve which was obtained by using standard solutions of a purified kallikrein of pig pancreas (Sanwa Kagaku Kenkyusho, Nagoya, Japan). Enzyme activity of urinary kallikrein was expressed in naphthyl units (NU). One NU is the amount of kallikrein which can hydrolyze 1.0 umol of Pro-Phe-Arg-NE per min. By using this method, the intraassay CV was $2.8 \%$. Kallikrein excretion rate was calculated from a 24-h urinary excretion of kallikrein divided by a 24-h CCr (GFR) using the same urine sample collected on the same day and expressed as $\mathrm{NU} / \mathrm{ml}$. The mean of two values for the kallikrein excretion rate obtained from the samples collected for 2 days was recorded in each subject.

Serum creatinine was measured in an Auto-Analyzer (SMAC I, Technicon, Tarrytown, NY, USA) by spectrophotometry (intraassay $\mathrm{CV}, 4.1 \%)$. Urinary creatinine and sodium were measured by spectrophotometry and ion-selective electrode method respectively, in an Astra 4 (Beckman, Fullerton, CA, USA) (intraassay CV, 2.8\% for creatinine and $0.9 \%$ for sodium). PRA [17] and PAC [18] were measured by radioimmunoassay using commercial kits (CEA-IRESORIN) (intraassay CV, 2.3\% for PRA and 3.6\% for PAC). Glycosylated haemoglobin $\mathrm{A}_{1 \mathrm{c}}$ was measured by high-performance liquid chromatography [19] on a cation-exchange minicolumn (Auto $A_{1 c}$ HA-8110, Kyoto Daiichi Kagaku, Kyoto, Japan) (intrassay CV, 2.2\%).

\section{Statistical analysis}

Average data are given as the mean \pm 1 standard deviation (SD). Statistical comparison of group means employed Student's t-test where appropriate. Regression lines were calculated by the least squares analysis and the coefficient of correlation (r) was tested. We also evaluated the contribution of the individual factors to the overall variability in systolic blood pressure or urinary kallikrein excretion by using a multiple linear regression program (JMA Research Institute Inc., Tokyo, Japan). A $p$ value less than $5 \%$ was considered statistically significant. All statistical analyses were done with a computer (PC-9801, NEC, Tokyo, Japan).

\section{Results}

The mean $( \pm S D)$ value for urinary kallikrein excretion in the Group B diabetic patients $(6.2 \pm 2.4 \mathrm{NU} /$ day, $\mathrm{n}=13)$ was significantly lower $(p<0.01)$ than in the control subjects $(12.8 \pm 3.4 \mathrm{NU} /$ day, $n=10)$, and even lower $(p<0.05)$ in the Group A patients $(9.4 \pm$ $3.4 \mathrm{NU} /$ day, $n=14$ ) (Fig. 1). Although the 24-h urinary excretion of kallikrein in Group A-N (9.3 \pm 3.4 NU/day, $n=10$ ) was similar to that in Group A-Hy $(9.5 \pm 3.3 \mathrm{NU} /$ day, $\mathrm{n}=4)$, the kallikrein excretion in Group B-Hy $(5.1 \pm 1.6 \mathrm{NU} /$ day, $\mathrm{n}=8)$ was significantly reduced $(p<0.05)$ as compared to that in Group B-N $(8.3 \pm 2.1 \mathrm{NU} /$ day, $n=5$ ) (Fig. 2). The mean values for the 24-h urinary excretion of sodium were $155 \pm$ $49 \mathrm{mmol} /$ day in control subjects, $157 \pm 43 \mathrm{mmol} /$ day in Group A and $140 \pm 49 \mathrm{mmol} /$ day in Group B, and there were no significant differences among the values. Similarly, there were no significant differences among the mean values for kallikrein excretion rate in control subjects $(9.9 \pm 4.3 \mathrm{NU} / \mathrm{ml})$, in Group A $(9.0 \pm 3.2 \mathrm{NU} / \mathrm{ml})$ and in Group B $(9.3 \pm 3.5 \mathrm{NU} / \mathrm{ml})$. However, the kallik- 
Table 2. Summarized data derived from multiple regression analysis obtained from 27 patients with Type 2 diabetes mellitus

\begin{tabular}{|c|c|c|c|c|c|c|}
\hline \multirow{2}{*}{$\begin{array}{l}\text { Dependent variables } \\
\text { Independent variables }\end{array}$} & \multicolumn{3}{|c|}{ 24-h urinary excretion of kallikrein } & \multicolumn{3}{|c|}{ Systolic blood pressure } \\
\hline & $\begin{array}{l}\text { Partial } \\
\text { regression } \\
\text { coefficient }\end{array}$ & $\begin{array}{l}\text { Standardized } \\
\text { partial } \\
\text { regression } \\
\text { coefficient }\end{array}$ & $\mathrm{F}$ & $\begin{array}{l}\text { Partial } \\
\text { regression } \\
\text { coefficient }\end{array}$ & $\begin{array}{l}\text { Standardized } \\
\text { partial } \\
\text { regression } \\
\text { coefficient }\end{array}$ & $\mathrm{F}$ \\
\hline Age & 0.098 & 0.235 & 1.85 & 0.338 & 0.085 & 0.94 \\
\hline Systolic blood pressure & -0.098 & -0.941 & $8.99^{\mathrm{b}}$ & - & - & - \\
\hline Diastolic blood pressure & 0.114 & 0.054 & 2.92 & 1.466 & 0.734 & $75.31^{\mathrm{b}}$ \\
\hline 24-h creatinine clearance & 0.033 & 0.182 & 0.86 & 0.022 & 0.013 & 0.01 \\
\hline Presence of nephropathy & -0.611 & -0.091 & 0.12 & 17.511 & 0.728 & $8.89^{b}$ \\
\hline 24-h urinary excretion of albumin & -0.000 & -0.004 & 0.00 & 0.002 & 0.051 & 0.20 \\
\hline 24-h urinary excretion of kallikrein & - & - & - & -1.685 & -0.176 & $3.67^{\mathrm{a}}$ \\
\hline
\end{tabular}

"Statistically significant at $p<0.05 ;{ }^{\text {b }}$ statistically significant at $p<0.01$

rein excretion rate in Group B-Hy $(7.7 \pm 3.3 \mathrm{NU} / \mathrm{ml})$ was significantly lower $(p<0.05)$ than that in Group B-N $(11.8 \pm 2.0 \mathrm{NU} / \mathrm{ml}$ ) (Fig. 3 ), whereas this value in Group A-Hy $(9.3 \pm 3.6 \mathrm{NU} / \mathrm{ml})$ was not significantly different from that in Group A-N $(8.9 \pm 3.0 \mathrm{NU} / \mathrm{ml})$.

Comparison of the urinary kallikrein excretion with clinical parameters assessed in the present study (24-h $\mathrm{CCr}$, systolic blood pressure, diastolic blood pressure, 24-h urinary excretion of albumin, haemoglobin $\mathrm{A}_{1 \mathrm{c}}$ ) revealed no significant correlation within each of the study groups (Group A, Group B diabetic patients and control subjects). However, there was a trend toward observations that 24-h urinary excretion of kallikrein was positively related $(r=0.275)$ to the 24 -h $\mathrm{CCr}$ and negatively $(r=-0.439)$ to the systolic blood pressure in the Group B diabetic patients.

The multiple regression analysis data derived from 27 diabetic patients are summarized in Table 2 . Systolic blood pressure was negatively related $(p<0.05)$ to the 24-h urinary excretion of kallikrein among the variables examined. However, both diastolic blood pressure and nephropathy were positively $(p<0.01)$ and 24-h urinary excretion of kallikrein was negatively $(p<0.05)$ related to the systolic blood pressure (Table 2). The following order of the power contributing to the overall variability in 24-h urinary kallikrein excretion or systolic blood pressure was found: systolic blood pressure $>24-\mathrm{h}$ $\mathrm{CCr}>$ age $>$ presence of nephropathy $>$ diastolic blood pressure $>24$-h urinary excretion of albumin for 24-h urinary excretion of kallikrein; and diastolic blood pressure $>$ presence of nephropathy $>24-h$ urinary excretion of kallikrein $>$ age $>24$-h urinary excretion of albumin $>24$-h CCr for systolic blood pressure. A similar trend toward the above observations was obtained when all study subjects $(n=37)$ were included.

The mean value for basal PRA in Group B-Hy $\left(0.7 \pm 0.6 \mathrm{ng} \cdot \mathrm{ml}^{-1} \cdot \mathrm{h}^{-1}\right)$ was significantly reduced $(p<$

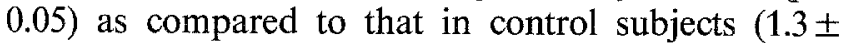
$\left.0.9 \mathrm{ng} \cdot \mathrm{ml}^{-1} \cdot \mathrm{h}^{-1}\right)$. The PRA after the stimulation with furosemide and ambulation in Group B-Hy $(1.8 \pm$ $1.8 \mathrm{ng} \cdot \mathrm{ml}^{-1} \cdot \mathrm{h}^{-1}$ ) was lower, but not significantly, than that in control subjects $\left(3.0 \pm 2.6 \mathrm{ng} \cdot \mathrm{ml}^{-1} \cdot \mathrm{h}^{-1}\right)$. The mean value for basal PAC in Group B-Hy $(5.3 \pm$ $3.2 \mathrm{ng} / \mathrm{ml})$ was similar to that in control subjects $(5.5 \pm$ $3.2 \mathrm{ng} / \mathrm{ml}$ ). The stimulation with furosemide plus ambulation increased the PAC to a similar extent both in the control subjects $(9.3 \pm 2.6 \mathrm{ng} / \mathrm{ml})$ and Group B-Hy diabetic patients $(10.5 \pm 3.4 \mathrm{ng} / \mathrm{ml})$.

\section{Discussion}

It has been demonstrated that urinary kallikrein is synthetized by the kidney [20-22]. Renal kallikrein is known to differ from plasma kallikrein in its biochemical, immunological and functional characteristics [11], and urinary kallikrein appears to be chemically similar to renal kallikrein [23]. Therefore, urinary kallikrein has been assumed to be an index of renal kallikrein secretion [24-26]. Previous studies have shown that urinary kallikrein excretion is decreased in patients with essential hypertension [24, 27], in spontaneously hypertensive rats [28], and in patients with hypertension associated with renal parenchymal disease [29], implying that an altered intra-renal activity of kallikrein-kinin system may exist in some forms of hypertension.

The observed decrease in urinary kallikrein excretion in diabetic nephropathy (Group B) is most likely attributable to renal parenchymal damage due to diabetes mellitus. A decrease in urinary kallikrein excretion has been documented in patients with renal parenchymal disease [29] and in experimental renal disease [30]. There was a trend toward observation that the 24-h urinary excretion of kallikrein was positively related to the 24-h CCr in the Group B diabetic patients, although the correlation did not reach a statistically significant level. Furthermore, no significant differences were found among the values for urinary kallikrein excretion rate expressed as factored by GFR in each of the study groups. These observations may suggest that renal impairment would affect urinary kallikrein excretion and that the low urinary kallikrein excretion in Group B would be a response to reduction in the nephron number due to diabetes mellitus. A decrease in urinary kal- 
likrein may indicate an altered tubular function in diabetic nephropathy, since kallikrein is localized in the convoluted distal tubules [31] and kinin is formed in the distal parts of the nephrons [32]. The relatively high kallikrein excretion rate in the Group B-N diabetic patients may be explained by acceleration of the production of renal kallikrein in order to maintain sodium and water excretion, or by the relatively good maintenance of renal tubular function as compared with glomerular function [31], or both.

A close relationship between the renal kallikreinkinin system and the renin-angiotensin-aldosterone system has been suggested by several investigators: urinary kallikrein is increased in primary aldosteronism [24], Bartter's syndrome [25], deoxycorticosterone-salt experimental hypertension [28] or upon aldosterone administration [26], whereas adrenalectomy reduces kallikrein excretion in rats [33]. Kaizu and Margolius [34] have shown that aldosterone increases kallikrein activity in rat kidney cell suspensions, while spironolactone decreases it. In diabetic nephropathy, PRA has been reported to be reduced [6] or to remain normal [8], and some diabetic patients are reported to have low PAC and low urinary excretion rates of aldosterone [35]. We observed that the PRA values before and after stimulation with furosemide and ambulation tended to be lower in the Group B diabetic patients with hypertension (B-Hy) than those in the control group. However, the value for PAC was not reduced in this group of the patients as compared to the control group, implying that a decrease in kallikrein excretion in patients with hypertension complicated by diabetic nephropathy might not be due to abnormality in the renin-angiotensin-aldosterone system.

Fristschka et al. [36] have reported that treatment with a $\beta$-receptor blocker, metoprolol, resulted in a decrease in urinary kallikrein excretion in essential hypertension. This observation implies that the synthesis or secretion of renal kallikrein may be partially controlled by a sympathetic tone or $\beta$-adrenergic receptor. Neuropathy is one of the common complications in diabetes mellitus [37], and the presence of diabetic autonomic neuropathy is more common in patients with nephropathy than those without [38]. Accordingly, an impaired autonomic nerve function is another likely cause of the lower kallikrein excretion observed in our patients with nephropathy, although the autonomic nerve function or $\beta$-adrenergic receptor sensitivity was not evaluated in the present study.

Although hypertension is more commonly seen in patients with diabetes mellitus than in non-diabetic subjects $[1-3,5]$, the precise mechanism(s) leading to hypertension still seems unclear. Our observation that urinary kallikrein excretion was reduced in patients with diabetes mellitus associated with nephropathy (Group B) as compared to those without nephropathy (Group A) suggests that production and/or secretion of renal kallikrein may decrease with the progression of diabetic nephropathy. Since correlations between urinary kallikrein activity and renal blood flow [39], sodium excretion [40] or water excretion [41] have been reported, the decrease in renal kallikrein secretion may be considered as a cause of sodium and water retention, which could lead to a rise in blood pressure. Nevertheless, it is not possible, with the present data, to know if the decreased urinary kallikrein excretion is a cause or a consequence of the condition combining diabetic nephropathy and high blood pressure. In this context, further studies are obviously required to clarify the possible role(s) of renal kallikrein in diabetic patients who do and do not develop and/or maintain hypertension with and without nephropathy. In addition, the interaction or counterbalance between this system and the renin-angiotensin-aldosterone system in diabetic patients associated with normotension or hypertension in the absence of nephropathy, and with normotension in the presence of nephropathy, should also be elucidated in future studies.

Acknowledgements. The authors wish to thank Ms. Kaori Narita and Noriko Togashi for their secretarial assistance, and Sanawa Kagaku Kenkyusho Co., Ltd., Nagoya, Japan, for their donation of the reagents for the measurement of urinary kallikrein acitivity used in this study. This work was supported by a grant-in-aid from the Ministries of Education and Science and of Human Health and Welfare, Japan

\section{References}

1. Moss AJ (1962) Blood pressure in children with diabetes mellitus. Pediatrics 130: 932-936

2. Pell S, D'Alonzo CA (1967) Some aspects of hypertension in diabetes mellitus. J Am Med Assoc 202: 104-110

3. Pell S, D'Alonzo CA (1971) Factors associated with long-term survival of diabetes. J Am Med Assoc 214: 1833-1844

4. White $P(1956)$ Natural course and prognosis of juvenile diabetes. Diabetes 5: $445-450$

5. Baba T, Murabayashi S, Aoyagi K, Sasaki K, Imamura K, Kudo M, Takebe K (1985) Prevalence of hypertension in diabetes mellitus: Its relation to diabetic nephropathy. Tohoku J Exp Med 145: $167-173$

6. Christlieb AR, Kaldany A, D'Elia JA (1976) Plasma renin activity and hypertension. Diabetes 25: 969-974

7. Perez GO, Lespier L, Jacobi J, Oster JR, Katz FH, Baamonde CA, Fishman L (1977) Hyporeninemia and hypoaldosteronism in diabetes mellitus. Arch Int Med 137: 852-855

8. Fernandez-Cruz A, Noth RH, Lassman MN, Hollis JB, Mulrow PJ (1981) Low plasma renin activity in normotensive patients with diabetes mellitus: Relationship to neuropathy. Hypertension 3: 87-92

9. Tomita K, Matsuda O, Ideura T, Shiigai T, Takeuchi J (1982) Renin-angiotensin-aldosterone system in mild diabetic nephropathy. Nephron 31: 361-367

10. Wilson TW, Tan LK (1985) Low plasma renin activity in diabetes: Relation to urine prostaglandin excretion. Diabetes 34: 145-150

11. Carretero OA, Scicli AG (1981) Possible role of kinins in circulatory homeostasis. Hypertension 3 (Suppl 1): 4-12

12. National Diabetes Data Group (1979) Classification of diagnosis of diabetes mellitus and other categories of glucose intolerance. Diabetes 28: 1039-1057

13. Miles DW, Mogensen CE, Gundersen HJG (1970) Radioimmunoassay for urinary albumin using a single antibody. Scand J Clin Lab Invest 26: 5-11 
14. Viberti GC, Hill RD, Jarrett RJ, Argyropoulos A, Mahmud U, Keen $H$ (1982) Microalbuminuria as a predictor of clinical nephropathy in insulin-dependent diabetes mellitus. Lancet 1: $1430-1432$

15. Mogensen CE, Christensen CK (1984) Predicting diabetic nephropathy in insulin-dependent patients. $\mathrm{N}$ Engl $\mathrm{J}$ Med 311: 89-93

16. Hitomi Y, Niinobe M, Fujii S (1980) A sensitive colorimetric assay for human urinary kallikrein. Clin Chim Acta 100: 275-283

17. Haber E, Koerner T, Page LB, Klinman B, Purnode A (1969) Application of a radioimmunoassay for angiotensin I to the physiologic measurements of plasma renin activity in normal human subjects. J Clin Endocrinol Metab 29: 1349-1355

18. Ogihara T, linuma K, Nishi K, Arakawa Y, Takagi A, Kurata K, Miyai K, Kumahara Y (1977) A non-chromatographic non-extraction radioimmunoassay for serum aldosterone. J Clin Endocrinol Metab 45: 726-731

19. Davis JE, McDonald JM, Jarrett L (1978) A high-performance liquid chromatography method for hemoglobin $\mathrm{A}_{1 \mathrm{c}}$. Diabetes 27 : 102-107

20. Nustad K, Vaaje K, Pierce JV (1975) Synthesis of kallikreins by rat kidney slices. Br J Pharmacol 53: 229-234

21. Roblero J, Croxatto H, Garcia R, Corthorn J, De Vito E (1976) Kallikrein-like activity in perfusates and urine of isolated rat kidneys. Am J Physiol 231: 1383-1389

22. Scicli AG, Carretero OA, Hampton A, Cortes P, Oza NB (1976) Site of kininogenase secretion in the dog nephron. Am J Physiol 230: $533-536$

23. Nustad K (1970) The relationship between kidney and urinary kininogenase. Br J Pharmacol 39: 73-86

24. Margolius HS, Geller RG, Pisano JJ, Sjoerdsma A (1971) Altered urinary kallikrein excretion in human hypertension. Lancet 2 : 1063-1065

25. Lechi A, Covi G, Lechi C, Mantero F, Scuro LA (1976) Urinary kallikrein excretion in Bartter's syndrome. J Clin Endocrinol Metab 43: 1175-1178

26. Rapelli A, Dessi-Fulgheri P, Mededdu P, Leoni C, Fiori C, Cocco F, Sanna G, Glorioso N (1982) Plasma active and inactive renin and urinary kallikrein in normal subjects in response to hydrochlorothiazide, spironolactone or aldosterone administration. Clin Exp Hypertens 4: 2273-2283

27. Elliot AH, Nazum FR (1934) The urinary excretion of a depressor substance (kallikrein of Frey and Kraut) in arterial hypertension. Endocrinology 18: 462-474

28. Keiser HR, Geller RG, Margolius HS, Pisano JJ (1976) Urinary kallikrein in hypertensive animal models. Fed Proc 35:199-202

29. Mitas JA, Levy SB, Holle R, Frigon P, Stone RA (1978) Urinary kallikrein activity in the hypertension of renal parenchymal disease. N Engl J Med 299: 162-165
30. Glasser RJ, Michael AF (1976) Urinary kallikrein in experimental renal disease. Lab Invest 34: 616-622

31. Ørstavik TB (1980) The kallikrein-kinin system in exocrine organs. J Histochem Cytochem 28: 881-889

32. Scicli AG, Gandolfi R, Carretero OA (1978) Site of formation of kinins in the dog nephron. Am J Physiol 234: F36-F40

33. Geller RG, Margolius HS, Pisano JJ, Keiser HR (1972) Effects of mineralocorticoids, altered sodium intake and adrenalectomy on urinary kallikrein in rats. Cir Res 31: 857-861

34. Kaizu T, Margolius HS (1975) Studies on rat renal cortical cell kallikrein. I. Separation and measurement. Biochim Biophys Acta 411: 305-315

35. DeLeiva A, Christlieb AR, Melby JC, Graham CA, Day RP, Leutscher JA, Zager PG (1976) Big renin and biosynthetic defect of aldosterone in diabetes mellitus. N Engl J Med 295: 639-643

36. Fritschka E, Gotzen R, Kittler R, Schoneshofer M (1984) Effect of metoprolol on 24-hour urinary excretion of adrenal steroids and kallikrein in patients with essential hypertension. Br J Pharmacol 81: $245-253$

37. Fraser DM, Campbell IW, Ewing DJ, Murray A, Neilson JMM, Clarke BF (1977) Peripheral and autonomic nerve function in newly diagnosed diabetes mellitus. Diabetes 26: 546-550

38. Dyrberg TM, Benn J, Sandahl CJ, Hilsted J, Nerup J (1981) Prevalence of diabetic autonomic neuropathy measured by simple bedside tests. Diabetologia 20: 190-194

39. Levy SB, Lilley JJ, Frigon RP, Stone RA (1977) Urinary kallikrein and plasma renin activity as determinants of renal blood flow: the influence of race and dietary sodium intake. J Clin Invest 60: $129-138$

40. Adetuyibi A, Milles IH (1972) Relation between urinary kallikrein and renal function, hypertension and exretion of sodium and water in man. Lancet 2: 203-207

41. Milles IH, Ward PE (1975) The relationship between kallikrein and water excretion and the conditional relationship between kallikrein and sodium excretion. J Physiol 246: 695-707

Received: 11 September 1985

and in revised form: 17 December 1985

Dr. Tsuneharu Baba

The Third Department of Internal Medicine

Hirosaki University School of Medicine

Zaifu-cho 5

Hirosaki City

Aomori-ken 036

Japan 